\title{
LETTERS
}

\section{Who assigns value in value- based insurance design?}

Public money should not be used to pay for prescription drugs of little to no medical value. To the extent that value-based insurance design, whereby drugs of lower medical value attract a higher copay, advances this proposition, it is an idea that has merit. ${ }^{1}$ However, there are also substantial problems with value-based insurance design that should give policymakers cause for concern.

First is how to determine value. In some cases, it is easy to assign value (e.g., insulin to treat type 1 diabetes is clearly a valuable drug); however, in other instances it is more difficult. As a 71-year-old man, I place a high value on using an $\alpha$-blocker because it allows me to sleep through the night without needing to get up and urinate. Where would $\alpha$-blockers fit into a value-based insurance design system? If they were deemed to be of low value after all they are certainly not life saving or even life extending - and had a high copay attached to them, then I might not be able to afford them, and my quality of life would not be as good.
More important is who is being penalized under a value-based insurance design system. Ideally, a prescription should be the result of a negotiation between the prescriber and the patient; however, most patients accept the decision of the prescriber that a particular medicine is necessary for their health. Unless we accept that patients demand a prescription for a lowvalue medicine and the prescriber acquiesces to that demand, it is the clinician who makes the decision about what drug to prescribe. But if that is a drug that is low value and has a high copay, it is the patient who has to pay the copay (i.e., the patient is penalized for the decision of the clinician). If we want to "steer" anyone away from low-value drugs, as Drs. Yeung and Morgan ${ }^{1}$ discussed in their CMAJ Analysis article, then it should be the people who write the prescriptions not the people who will be taking them who should be affected. Perhaps it should be the clinicians who are responsible for the copay, not the patients.

\section{Joel Lexchin MD MSc}

Emergency physician, University Health Network and Faculty of Medicine, University of Toronto, Toronto, Ont.
Cite as: CMAJ 2020 January 6;192:E15. doi: $10.1503 / \mathrm{cmaj} .73617$

\section{Reference}

1. Yeung K, Morgan SG. Should national pharmacare apply a value-based insurance design? CMAJ 2019;191:E811-5.

Competing interests: In 2016-2019, Joel Lexchin was a paid consultant on 2 projects: one looking at developing principles for conservative diagnosis (Gordon and Betty Moore Foundation) and a second deciding what drugs should be provided free of charge by family physicians (Government of Canada, Ontario Supporting Patient Oriented Research Support Unit and the St. Michael's Hospital Foundation). He also received payment for being on a panel at the American Diabetes Association, for a talk at the Toronto Reference Library, for writing a brief in an action for adverse effects of a drug for Michael F. Smith (lawyer) and from the Canadian Institutes of Health Research (CIHR) for presenting at a workshop on conflict of interest in clinical practice guidelines. He is currently a member of research groups that are receiving money from $\mathrm{CIHR}$ and the $\mathrm{Na}$ tional Health and Medical Research Council of Australia. He is a member of the Foundation Board of Health Action International and the board of Canadian Doctors for Medicare. He receives royalties from University of Toronto Press and James Lorimer \& Co. Ltd. for books he has written. 